\title{
Experimental Analysis of Horizontal Turbulence of Flow over Flat and Deformed Beds
}

\begin{abstract}
Donatella Termini
Dipartimento di Ingegneria Civile, Ambientale, Aerospaziale, dei Materiali - University of Palermo; Viale delle Scienze, 90128 Palermo - Italy, Tel: ++39/091/23896522; e-mail: donatella.termini@unipa.it
\end{abstract}

(Received July 15, 2015; revised November 26, 2015)

\begin{abstract}
Laboratory experiments in a straight flume were carried out to examine the evolution of large-scale horizontal turbulent structures under flat-bed and deformed-bed conditions. In this paper, the horizontal turbulence of flow under these conditions is analyzed and compared. The conditioned quadrant method is applied to verify the occurrence of turbulent events. The distributions of horizontal Reynolds shear stress and turbulent kinetic energy are also presented and discussed. Results show the occurrence of an "initial" sequence of horizontal vortices whose average spatial length scales with the channel width. Under deformed-bed conditions, this spatial length does not change.
\end{abstract}

Key words: open-channel flow, flow turbulence structure, burst cycle, bed forms, laboratory experiments

\section{Introduction}

The understanding of the coupling between near-wall turbulence and sediment transport has been a subject of great interest for many years. The dynamics of the near-wall turbulence may cause the bed to deform. Bed deformation, in turn, perturbs the main flow and affects the overall flow resistance and the sediment transport rate (Sukhodolov et al 2011). Prediction of flow and sediment transport over bed forms is still today a major obstacle to the solution of sedimentation problems in alluvial channels (ASCE Committee 2002). Several studies have been conducted to examine the dynamics of coherent structures in the wall region (among others, Nezu and Rodi 1986, Robinson 1991, Nezu and Nakagawa 1993, Shvidchenko and Pender 2001). But the role played by coherent turbulent structures in sediment transport processes is still a focus of scientific discussion (Adrian and Marusic 2012).

It is currently well known that the near-wall turbulence is dominated by intermittent three-dimensional turbulent structures that evolve at different places and times, maintaining a common coherent pattern (Pope 2000). During the evolution of a coherent turbulent structure, a small-scale eddy develops into a large-scale eddy, following 
a life cycle which includes birth, development, and breakdown (burst). Large-scale coherent vortices are generated by the amalgamation of smaller-scale structures that grow in the outer layer, possibly interacting with pre-existing large-scale vortical motions (Nezu and Nakagawa 1993), until they disintegrate (burst) (Yalin 1992). Consequently, turbulent events linked to bursting motions are not just restricted to the wall region, but they may appear in the outer region as manifestation of large-scale eddies (among others, Grass 1971, Kanani et al 2010). Thus, in this work, the term "burst cycle" (or simply "burst") indicates the evolution of a large-scale coherent structure during its life cycle.

There is an ongoing debate on the regularity of macroturbulent fluctuations and the interpretation of their evolution. In fact, information derived from a review of the experimental literature provides contradictory evidence: some authors have derived from laboratory and field studies a regular spatial scale in turbulent fluctuations (e.g. see Nezu and Nakagawa 1993, Cellino and Graf 1999, Kanami et al 2010), whereas other authors have not detected any regular period and have supposed that coherent structures are randomly distributed in time and space (among others, Nikora and Smart 1997, Nikora and Goring 1999).

A review of the advances in the study of wall turbulence over the past two decades can be found in Adrian and Marusic (2012). From this review, it is clear that many kinds of coherent structures have been identified, and different explanations of how they are generated exist in the literature. Moreover, investigations of interactions across the scales of turbulent motions are needed (Adrian and Marusic 2012).

Turbulent events can be vertical (i.e. determined by eddies whose axes of rotation are perpendicular to the vertical plane - referred to hereafter as vertical vortices) or horizontal (i.e. determined by eddies whose axes of rotation are perpendicular to the vertical plane - referred to hereafter as horizontal vortices).

In the past decades, much effort has been made to analyze vertical vortices. Most studies were conducted in laboratory channels with smooth beds and side-walls (among others, Steffler et al 1985, Nezu and Rodi 1986). There is a general consensus that the streamwise length of a vertical burst cycle scales with the outer variable $h$ (i.e. the water depth) (Shvidchenko and Pender 2001). Thus, recently, a great deal of effort has been made to investigate the role played by vertical large-scale coherent structures in the development of bed forms (such as dunes) whose length scales with the water depth (among others, Lyn 1993, Bennet and Best 1995, Bennet et al 1997, Holmes and Garcì 2008, Mazumder et al 2009). On the other hand, from these studies it is clear how the presence of localized topographic gradients affects the evolution of flow turbulence structures.

Horizontal vortices have not yet been the focus of directed and systematic research. Only recently, research has been devoted to the development of a proper understanding of the dynamics of horizontal large-scale bursts and their consequences in river morphodynamics. 
As indicated by previous studies carried out in natural rivers (e.g. see Yokosi 1967) and in laboratory channels (e.g. see Utami and Ueno 1991), horizontal bursts scale with the outer variable $B$ (i.e. the channel width). Thus, Yalin (1992) argued that the analogous of the vertical large-scale burst cycle could be valid for the horizontal large-scale burst cycle. He supposed (see also da Silva 2006) that the horizontal vortices originate near the banks and the free surface (where the horizontal shear stresses are the largest). Then the vortices grow in size and are conveyed downstream and away from the banks (towards the opposite banks) by the mean flow. After traveling a distance equal to the length of a burst cycle (i.e. the distance between two consecutive "birth places" of bursts), these vortices disintegrate into smaller ones and return to the original banks. In particular, as indicated by Kanani et al (2010), an ejection event should be related to low momentum fluid which travels towards the opposite bank, whereas a sweep event should be related to high momentum fluid which travels towards the original bank.

Thus, Yalin (1992) (see also da Silva 2006, Kanani et al 2010) suggested that some morphological features (such as alternate bars and/or meanders), whose length scales with the channel width (as shown, among others, by Colombini et al 1987, Yalin 2002), initiate because of the large-scale horizontal bursts.

Certainly, the understanding of how these structures originate and create motions that transport momentum can be expected to improve the ability to predict the aforementioned behavior.

Because in completely uniform flow the probability of bursting processes (vertical and/or horizontal) could be equal in any location and time interval, Yalin (1992) also established that there must be a "location of preference" in the flow (i.e. local discontinuity on the bed and/or banks) that increases the occurrence frequency of burst cycles.

Some researchers have focused their attention on large-scale horizontal vortices that are generated in steady compound open-channel flows near the junction between the main channel and floodplains (among others, Tamai et al 1986, Nezu and Nakayama 1997). These researchers have related the generation of these horizontal vortices to the presence of an inflectional point (i.e. a shear instability) in the horizontal distribution of the primary mean velocity. On the other hand, coherent horizontal vortices resulting from shear instability have also been observed at the edge of a vegetated floodplain (Nezu and Onitsuka 2002) or at the interface of a porous layer (White and Nepft 2007). Furthermore, studies conducted in this field have also highlighted the existence of a strong interaction between coherent large-scale horizontal vortices and secondary currents that are generated either by the anisotropy of turbulence in straight channels (Nezu and Nakayama 1997, Albayrak 2008) or by curvature in meandering channels (e.g. see Sanjou and Nezu 2009). Numerical simulations have also been conducted by applying 2-D LES (e.g. see Nadaoka and Yagi 1998) and /or 3-D models (e.g. see Hosoda et al 1999) in order to examine the hydrodynamic effect of the momentum exchanges of horizontal vortices and their relation with secondary cur- 
rents. However, the understanding of how secondary currents and turbulence depend on each other is still unclear.

The point is that the lack of a proper understanding of the dynamics of coherent large-scale horizontal structures makes it difficult to determine their role in morphological phenomena occurring in rivers.

The aforementioned considerations motivate the need to improve the existing knowledge of the dynamics of horizontal turbulence structures and their action in sediment transport processes.

The work presented in this paper is part of a broader research project aimed at examining the dynamics of horizontal coherent structures (for different hydraulic and wall roughness conditions) and, where possible, at verifying the role played by these structures in bed deformation. In particular, the present paper complements previous works conducted by Termini and Sammartano (2008, 2009). Specifically, the goal of the present study is to compare the occurrence of ejection and sweep events in the same channel under flat-bed (initial) and deformed-bed conditions. This makes it possible to identify any changes in flow and turbulent events due to bed conditions, and thus to gain some insight into the coupling between flow turbulence and bed deformation.

\section{Experimental Procedure and Methodologies}

The experiments were carried out in a recirculating straight flume, $7 \mathrm{~m}$ long and 0.40 $m$ wide, specially constructed for this purpose at the laboratory of the Dipartimento di Ingegneria Civile, Ambientale, Aereospaziale, dei Materiali - University of Palermo (Italy). The channel banks were rigid and made of Plexiglass strips. On the side walls, a discontinuity at the junction of two different types of Plexiglass strips was inserted in a section (called "initial section") $1.0 \mathrm{~m}$ distant from the upstream end of the channel. Two runs were conducted in a turbulent subcritical flow with flow discharge of 0.013 $\mathrm{m}^{3} / \mathrm{s}$ and initial longitudinal bed slope of $0.45 \%(h=$ overall initial uniform water depth $=0.0515 \mathrm{~m} ; u^{*}=$ shear flow velocity $=\left(g R_{h} S\right)^{1 / 2}=0.0425 \mathrm{~m} / \mathrm{s}-$ with $g=$ gravitational acceleration and $R_{h}=$ hydraulic radius; $U m=$ cross-sectional mean streamwise velocity $=0.63 \mathrm{~m} / \mathrm{s}, F r=(U m / g h)^{1 / 2}=$ Froude number $=0.89, \operatorname{Re}=U m h / v=$ Reynolds number $=32538 ; R e^{*}=u^{*} k_{s} / v=$ roughness Reynolds number $=110.5-$ with $k_{s}=$ bed roughness set equal to $2 D_{50}$ in accordance with Yalin 1992).

Water was supplied through a submersible pump installed in a downstream reservoir. A tailwater weir, positioned at the downstream end of the flume, made it possible to adjust the water depth. The bed surface was made of quartz sand $\left(D_{50}=\right.$ median sediment diameter $=0.65 \mathrm{~mm}, \sigma_{g}=$ geometric standard deviation $\left.=1.28\right)$.

The first run (referred to hereafter as "R1") was conducted over the flat and rigid bed surface. During R1, detailed measurements of flow velocity components were carried out. Then, a mobile-bed run was conducted under the same hydraulic conditions as those in R1 in order to obtain the deformed-bed configuration. Thus, R1 can 


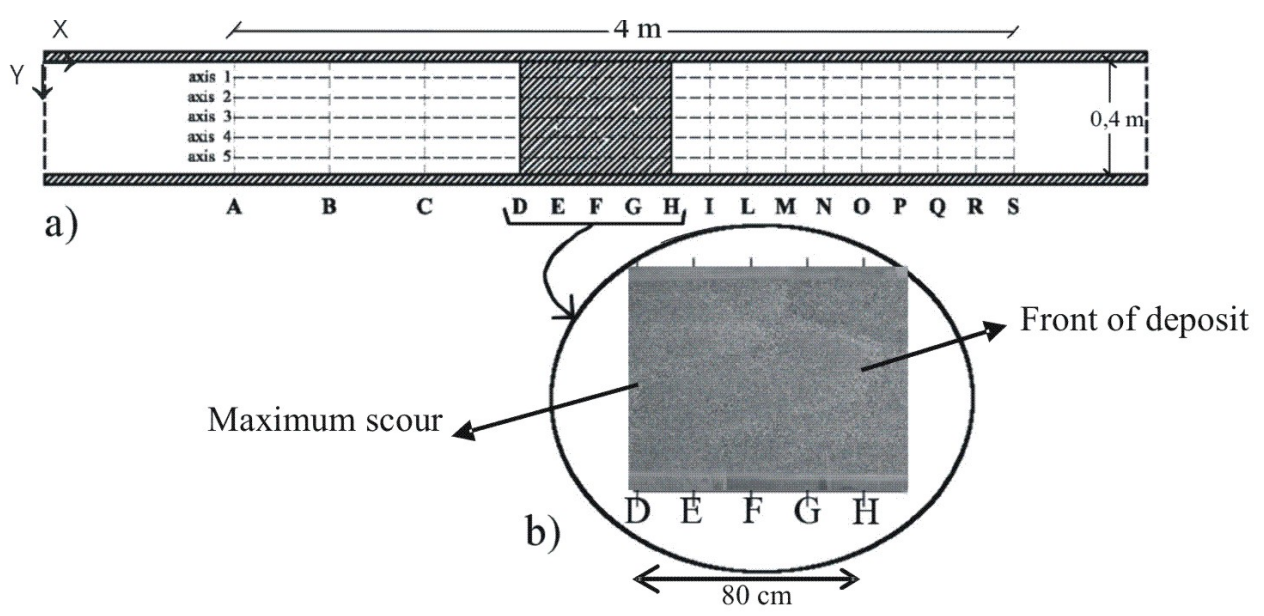

Fig. 1. Scheme of measurement cross-sections and longitudinal measurement axes

be considered the pre-deformed-bed configuration. During the mobile-bed run, the sand was recycled together with the stable discharge by the aforementioned recycling pumping circuit. Furthermore, the bed topography was measured along five longitudinal axes (see Figure 1a) with a profile indicator by Delft Hydraulics (accurate to $0.1 \mathrm{~mm}$ ) mounted on a carriage running along slides parallel to the channel banks. At the end of the experiment (lasting about 7 hours), the bed was covered by alternating regions of scour holes and deposit fronts. The position of scour hole/deposit front sequences was measured both by a graduated rule fixed to the Plexiglas side walls of the channel and by the profile indicator (more details can be found in Termini 2005, Termini and Lo Re 2006, Termini and Sammartano 2009). Then, the deformed bed surface was impregnated with spray paint, and another run (referred to hereafter as "R2") was conducted over the rigid and deformed bed (under the same hydraulic conditions as those in R1) in order to measure the flow velocity field. The sketch views of the bed configuration in R1 and R2 are shown in Figure 2. This figure shows a photograph of the channel reach (between sections $\mathrm{D}$ and $\mathrm{H}$ ) where the alternating scour-deposit regions were clearly distinguishable. Both by direct observation and by correlation analysis, it was determined that the distance between the maximum scour and the deposit front was around $80 \mathrm{~cm}$. This can also be seen in Figure 2 (note that the sections are spaced $20 \mathrm{~cm}$ apart). The following analysis concerns the channel reach between sections D and $\mathrm{H}$ (length $L s=0.80 \mathrm{~m}$ - see Figure 1), where a sequence scour hole/deposit front was particularly distinct.

During both runs (R1 and R2), the instantaneous flow velocity components were measured along 5 verticals of 17 measurement cross-sections (sections $\mathrm{A} \div \mathrm{S}$ in Figure 1), so that 5 longitudinal measurement axes were considered (see Figure 1). In the present work, attention is restricted to the longitudinal measurement axis near the right bank (axis 1) and to the measurement axis coinciding with the channel axis 


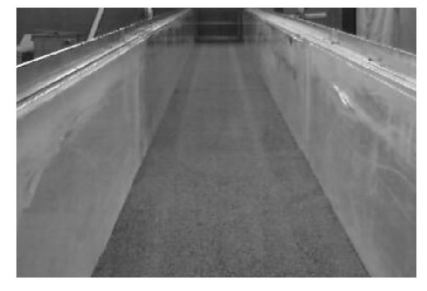

a)

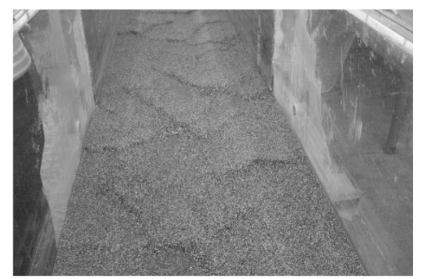

b)

Fig. 2. Sketch of the channel bed configuration: a) flat bed; b) deformed bed

(axis 3). The first four sections (A, B, C and D) were spaced about $50 \mathrm{~cm}$ or so; along the reach $\mathrm{D}-\mathrm{S}$ the distance between two consecutive sections was about 20 $\mathrm{cm}$. The streamwise and transverse velocity components were measured using a 2D side-looking Acoustic Doppler Velocimeter (ADV) by SonTek Inc. at points spaced $3 \mathrm{~mm}$ apart (this interval was selected to obtain a fine measurement grid consistent with the size of the sampling volume) along each measurement vertical. The sampling volume was approximately $0.25 \mathrm{~cm}^{3}$, and the sampling frequency rate was $F s=25$ Hz. In accordance with Rodriguez and Garcìa (2008), the record length for each point was selected as an order of at least 600 times the cross-sectional macro timescale of the flow in the streamwise direction, $T s=0.77 h / U m=0.07 \mathrm{~s}$ (see in Nezu and Nakagawa 1993) which also served to verify that a constant local mean velocity was obtained (see also Carollo et al 2005). Thus, the measurements consisted of approximately 80 -second-long records. The data collected were characterized by an average signal-noise ratio SNR of $45 \mathrm{~dB}$ and a minimum value of the data cross-correlation coefficient greater than $80 \%$.

The measurement instrument was mounted on a carriage that moved in the transverse direction with a step of $1 \mathrm{~mm}$, controlled by a 1D-dimensional Motion Control System (by MICOS s.r.l.). The movement of the motion control system and the acquisition of data were synchronized by a code in the Labview environment.

\section{Horizontal Flow Velocity Field}

\subsection{Distributions of Time-averaged Velocities}

The time series of the flow velocity components, $u_{i}(i=1$ in streamwise direction and $i=2$ in transverse direction) were used to compute the corresponding time-averaged components $U_{i}$. It should be clear that, according to the orientation of the measurement instrument, the positive directions of the velocity vectors are concordant with the reference system of Figure 1. Figure 3 ( $\mathrm{a}$ and $\mathrm{b}$ ) shows the contour lines of $U_{i}$ (with $i=1,2$ ) near the bed (i.e. at levels $z=z_{b}$, where $z_{b}=1 \mathrm{~cm}$ in R1 and $z_{b}=0.7$ $\mathrm{cm}$ in R2, which were consistent with the experimental and measurement conditions) normalized by the mean velocity $U m$. Furthermore, the horizontal distributions of 
the longitudinal component $U_{1}$, estimated under the flat-bed conditions (R1), are also reported in Figure 3. This figure shows that there is a notable horizontal velocity gradient $\partial U_{1} / \partial y$ and the distribution of $U_{1}$ varies along the channel reach examined. In sections $\mathrm{D}$ and $\mathrm{H}$ the distributions of $U_{1}$ have a reduced axial velocity (i.e. two peak values) and, thus, two inflection points. Along the reach between sections $\mathrm{E}$ and $\mathrm{G}$, the peak values move towards the channel axis. The presence of the inflection points suggests strongly that twin horizontal vortices are generated, in accordance with previous works (Nezu et al 1999 - see also Nezu et al 2003 and Sonjou and Nezu 2009). It should be noted that the two inflection points occur in sections spaced about $80 \mathrm{~cm}$ apart.
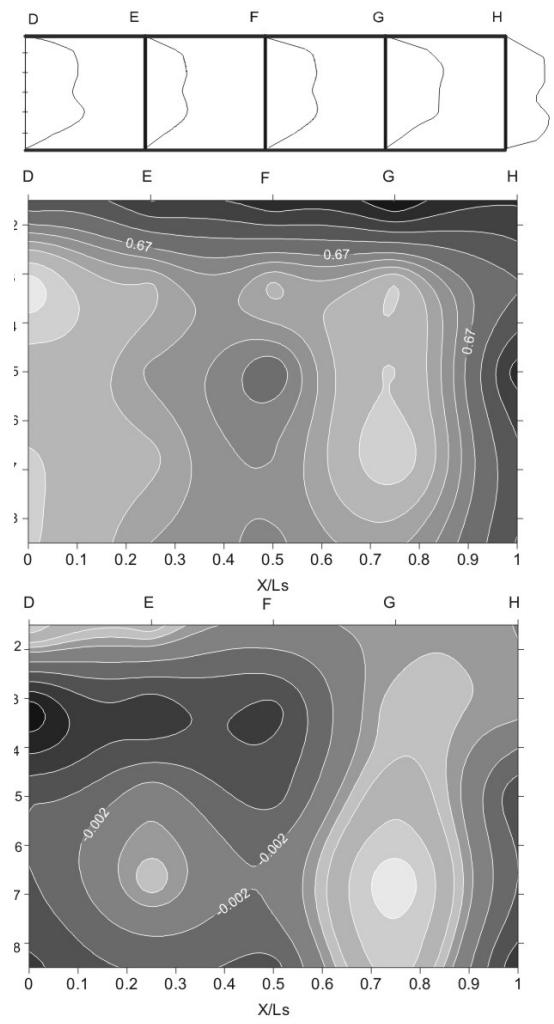

a)
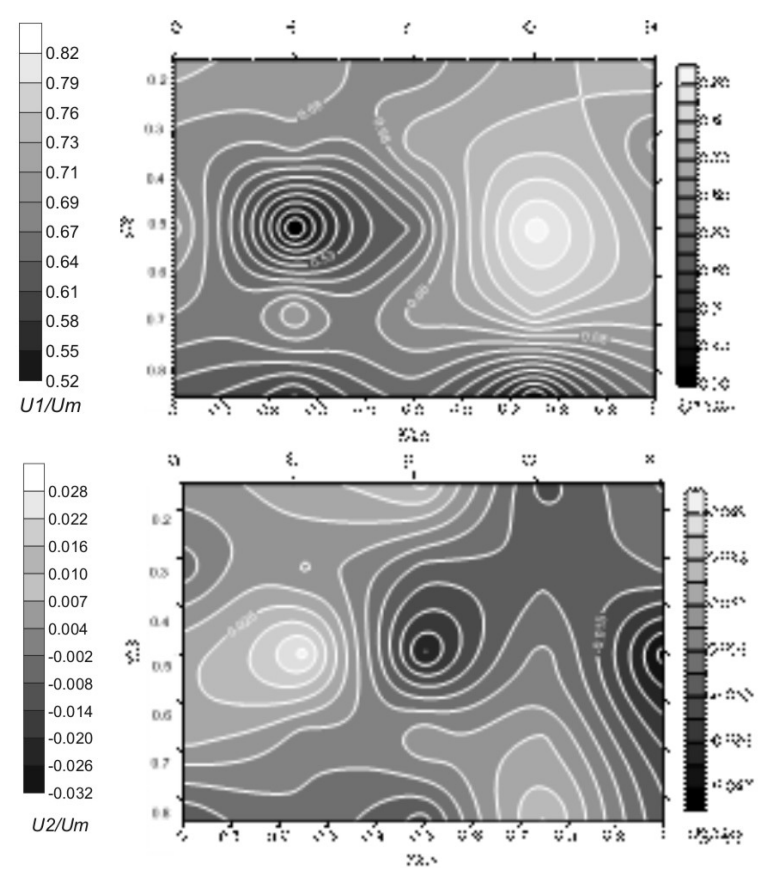

b)

Fig. 3. Contour lines of the normalized time-averaged streamwise and transverse velocity components: a) flat bed; b) deformed bed

Figure $3 \mathrm{a}$ also shows that there is a positive region of the transverse component, $U_{2}$, in section $\mathrm{G}$ and at the channel axis in section $\mathrm{E}$, whereas negative regions of $U_{2}$ are found near the banks in sections $\mathrm{D}, \mathrm{E}$, and $\mathrm{F}$, as well as near the right bank in section $\mathrm{H}$. In R2 (Figure $3 \mathrm{~b}$ ), the patterns of $U_{1}$ and $U_{2}$ are similar to those observed 
in R1, but more accentuated and slightly shifted downstream. Thus, it seems that bed deformation enhances the initial pattern of the horizontal flow velocity field along the channel reach examined. On the basis of this result, it could be supposed that the initial horizontal velocity pattern (Figure $3 a$ ) is maintained over time.

\subsection{Power Spectrum}

Power spectrum is commonly used to define the distribution of energy in the signal across frequencies. In this work, power spectra were obtained by the Fast Fourier Transform (FFT) technique (Pope 2000) with the help of the Matlab (v. 8.1) code. The algorithm determines the power spectral density by first forming a periodogram; the FFT length (rectangular window) is set to the next power of 2 greater than the input signal length, and the output is set to the magnitude squared (which gives the total energy contribution among various frequencies).

Figure 4 reports the power spectra of the time series $u_{1}\left(\right.$ at $\left.z=z_{b}\right)$ against the normalized frequency for both runs (sections D, E, F, G, and $\mathrm{H}-$ axis 3 ). The frequency axis is normalized by the ratio of the characteristic length scale $B$ and the mean flow velocity $U m$. The frequency axis should thus be read as the Strouhal number, St. Power spectra are plotted on log-log scales to facilitate the appreciation of the entire spectrum. (It should be noted that the unit of the velocity spectrum is quantity squared/frequency, i.e. $\mathrm{m}^{2} / \mathrm{s}$ ).

Figure 4 shows that higher peaks occur at lower frequencies. Furthermore, all profiles are similar. It can be seen that the peak value of the profile decays as one passes from section $D$ to section $F$, and then the peak value increases again until section $G$ is reached. Under deformed-bed conditions (R2), the higher peak occurs downstream of the front of deposit (section H). Thus, it seems that the front of deposit is the "location of preference" for low-frequency high-spectrum motions. In Figure 4, it can also be observed that under undeformed-bed conditions (R1) the dominant dimensionless frequency is $\cong 0.13$, which gives a dimensional frequency of the order of $0.19 \mathrm{~Hz}$, whereas under deformed-bed conditions, the dominant dimensionless frequency is $\cong 0.10$, which gives a dimensional frequency of around $0.16 \mathrm{~Hz}$. Estimating the period as the inverse of the dominant frequency, one obtains a corresponding value of around $5 \mathrm{~s}$ for undeformed-bed conditions and around $6 \mathrm{~s}$ for deformed-bed conditions.

Furthermore, the analysis suggests that in R2 (i.e. when the bed is deformed) the "location of preference" for low-frequency high-spectrum motions is found downstream of the front of deposit. This behavior supports Yalin's (1992 - page 78) view that bed forms lead to the "regularization" of horizontal turbulence.

It should be noted, however, that although the estimated power spectrum allows us to extract events associated with the peaks, it is not always an appropriate tool for capturing the periodicity of coherent structures. In fact, according to Lewalle et al (2000), if the turbulent field is determined by the coexistence of different types of 

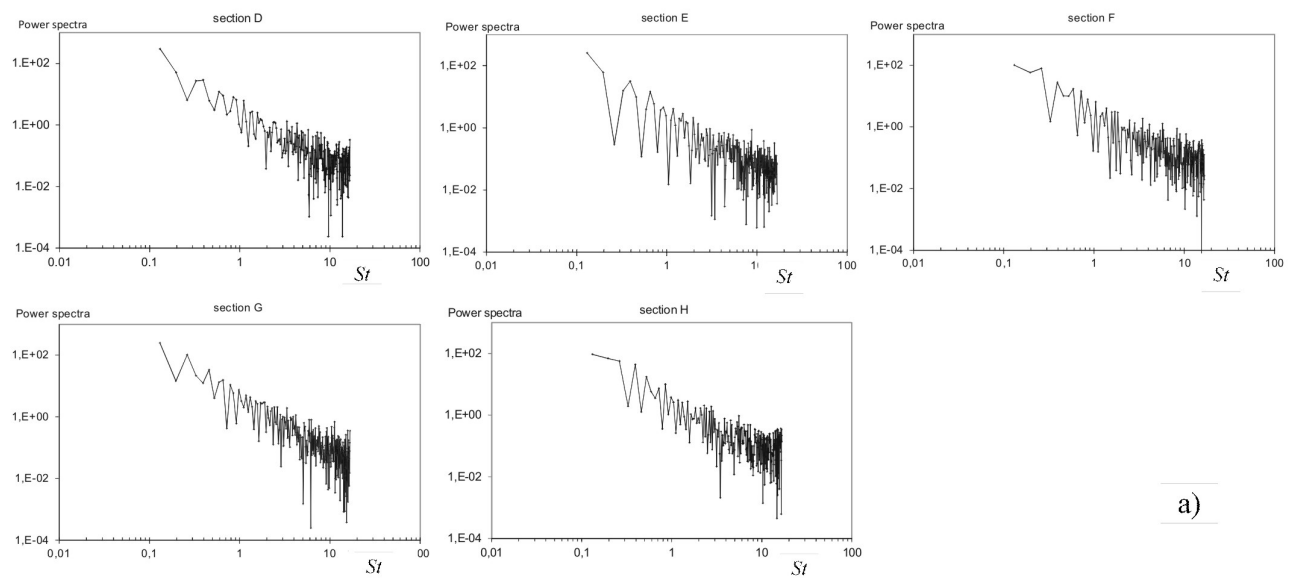

a)
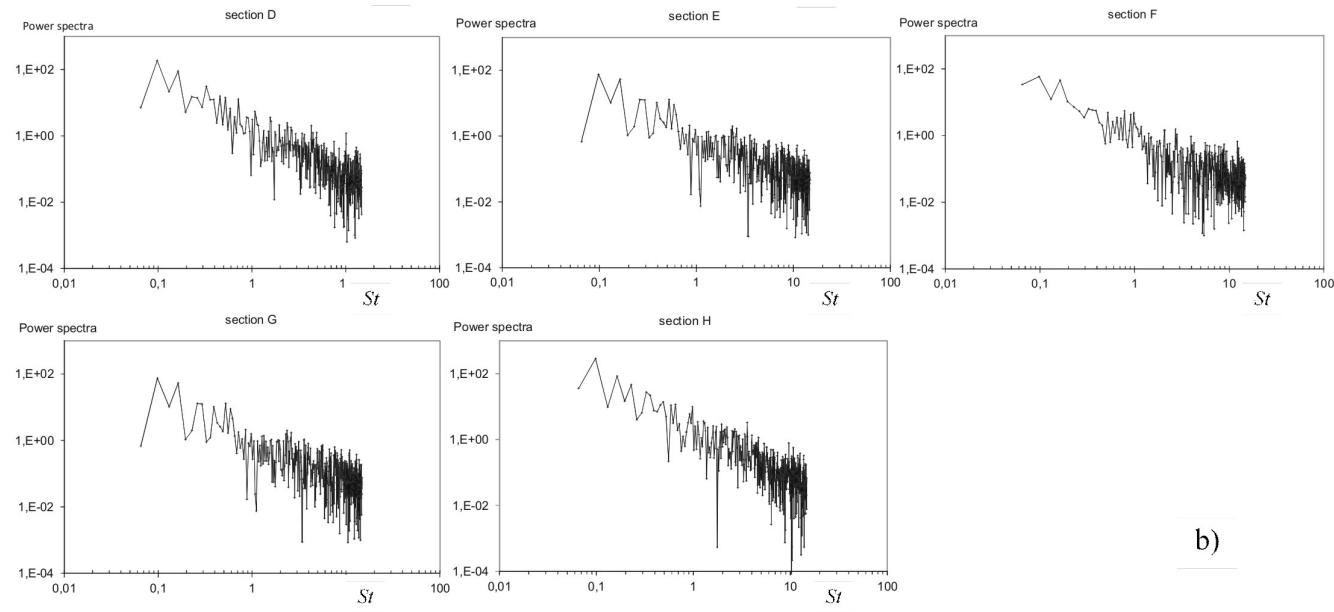

b)

Fig. 4. Power spectra of $u_{1}$ : a) flat bed; b) deformed bed

turbulent structures, it is possible that the coherent signal could be partially obscured (Balakumar and Adrian 2007).

For this reason, in the present work, other techniques have also been applied to detect the coherent motion.

\section{Horizontal Turbulence Structures}

\subsection{Occurrence Frequency of Turbulent Events}

The qualitative description of turbulence events is performed by applying the quadrant analysis (Lu and Willmarth 1973, Nezu and Nakagawa 1993), whereby events can be classified according to the sign of the components of the turbulent fluctuations. In an attempt to investigate the complicated dynamics of the 3-D horizontal structure, the analysis is extended over the whole water depth. Particular attention is paid to ejection 
and sweep events which - as it should be clear from the Introduction - play the most important role in sediment transport processes.

At each measurement point, the instantaneous turbulent fluctuation components, $u_{i}^{\prime}(i=1,2)$, were determined as deviations of the instantaneous measured flow velocity components from the corresponding time-averaged values: $u_{i}^{\prime}=u_{i}-U_{i}$.

As should be clear from the Introduction, in accordance with Kanani et al (2010), in this work an ejection event is related to low momentum fluid that travels towards the opposite bank, whereas a sweep event should be related to high momentum fluid traveling towards the original bank. Thus, it is assumed that an ejection event is characterized by low-speed fluid movement (instantaneous local velocity lower than the time-averaged local velocity, i.e. $\left.u_{1}^{\prime}<0\right)$ away from the side-wall $\left(u_{2}^{\prime}>0\right)$, and a sweep event is due to high-speed fluid movement $\left(u_{1}^{\prime}>0\right)$ towards the side-wall $\left(u_{2}^{\prime}<0\right)$. Inward interactions are determined by low-speed fluid movement $\left(u_{1}^{\prime}<0\right)$ towards the side-wall $\left(u_{2}^{\prime}<0\right)$ and outward interactions by high-speed fluid $\left(u_{1}^{\prime}>0\right)$ arising far from the side-wall $\left(u_{2}^{\prime}>0\right)$. Consequently, negative values of the instantaneous products $\left[u_{1}^{\prime} u_{2}^{\prime}\right]$ correspond to ejection and sweep events, whereas positive values of the instantaneous products $\left[u_{1}^{\prime} u_{2}^{\prime}\right]$ correspond to inward and outward interactions.

From the aforementioned, it is clear that ejection and sweep events, which contribute to the production of turbulence and Reynolds stress (Cantwell 1981, Nezu and Nakagawa 1993, Nelson et al 1995), play the most important role in erosion, entrainment, and transport of sediment particles (Garcìa et al 1996).

The instantaneous $\left[u_{1}^{\prime}, u_{2}^{\prime}\right]$ plane is composed of four quadrants, each of which represents a turbulent event ( $\mathrm{Lu}$ and Willmarth 1973). In order to isolate the contribution of extreme events within each quadrant, a conditional averaging procedure (Nezu and Nakagawa 1993, Cellino and Lemmin 2004) was applied and an exclusion hole was identified on the $\left[u_{1}^{\prime}, u_{2}^{\prime}\right]$ plane. Such an exclusion hole is bounded by the hyperbolic curves:

$$
\left|u_{1}^{\prime} \cdot u_{2}^{\prime}\right|=q \sqrt{{\overline{u_{1}^{\prime}}}^{2}} \sqrt{{\overline{u_{2}^{\prime}}}^{2}},
$$

where $q$ represents the threshold level, and the over-bar indicates the time-averaged value. Very small values of $q$ permit one to select strong and weak events; whereas large values of $q$ are used to select the strongest events.

Thus, a discriminating function $I_{k, q}$ (the index $k=\mathrm{I}$, II, III, IV indicates the quadrant in which the generic event falls) has been introduced to filter the instantaneous data set $\left[u_{1}^{\prime}, u_{2}^{\prime}\right]$. The function $I_{k, q}$ is defined as follows:

$$
I_{k, q}=\left\{\begin{array}{l}
1, \text { if the couple }\left[u_{1}^{\prime}, u_{2}^{\prime}\right] \text { falls in the } k-\text { th quadrant } \\
0, \text { otherwise }
\end{array}\right.
$$

Thus, the contribution from each quadrant has been determined by the discriminating function (2). The determination of $q$ is more or less arbitrary, and, in fact, dif- 
ferent values of $q$ are used in the literature. For example, Nakagawa and Nezu (1981) used two different values of $q$ to detect ejection $(q=2)$ and sweep events $(q=1.1)$. Other authors (e.g. see Cellino and Lemmin 2004, Mazumder et al 2009) suggested using a unique value of $q$ to define the exclusion region in each quadrant. Cellino and Lemmin (2004) compared the occurrence of turbulent events computed for four values of $q(q=0,1,2,3)$ and obtained the best representation for ejection events by setting the value of the threshold level at $q=3$. More recently, Mazumder et al (2009) compared the occurrence of turbulent events for three values of the threshold level $q(q=0,2,6)$ and determined how the relative intensity of each event for $q>0$ significantly increases as $q$ increases.

Termini and Sammartano $(2007,2009)$ used velocity data collected under the same hydraulic conditions as those of R1 and compared the occurrence of turbulent events obtained for values of the threshold levels $q(q=0,0.3,0.7,1.0,1.5)$ lower than those suggested by Mazumder et al (2009). Termini and Sammartano (2007, 2009) observed that when $q=0$ (no exclusion hole) the occurrence of each event is not clearly distinguishable. Furthermore, they found that although high values of the threshold level $q$ allowed them to select the strongest events, the total number of couples $\left[u_{1}^{\prime}, u_{2}^{\prime}\right]$ decreased so much that the contribution region from each quadrant became meaningless. On the basis of this result, Termini and Sammartano $(2007,2009)$ suggested that the threshold level $q=1$ be used for the same data set to reach a good compromise between the clear identification of the events and the preservation of a number of couples $\left[u_{1}^{\prime}, u_{2}^{\prime}\right]$ significant for the analysis.

Thus, by assuming the aforementioned value of the threshold level $q$, the filtered time series $\left[u_{1, f}^{\prime}, u_{2, f}^{\prime}\right]$ were obtained as:

$$
u_{1, f}^{\prime}, u_{2, f}^{\prime}=\left|u_{1}^{\prime} \cdot u_{2}^{\prime}\right| \cdot I_{k, 1}>\sqrt{{\overline{u_{1}^{\prime}}}^{2}} \cdot \sqrt{{\overline{u_{2}^{\prime}}}^{2}} .
$$

The filtered time series $\left[u_{1, f}^{\prime}, u_{2, f}^{\prime}\right]$ were used to estimate the normalized occurrence frequency, $f_{k}$, for the event types related to different quadrants:

$$
f_{k}=\frac{\sum_{t=0}^{T} I_{k, 1}}{\sum_{t=0}^{T} I_{\mathrm{I}, 1}+\sum_{t=0}^{T} I_{\mathrm{II}, 1}+\sum_{t=0}^{T} I_{\mathrm{III}, 1}+\sum_{t=0}^{T} I_{\mathrm{IV}, 1}} ; \quad k=\mathrm{I}, \mathrm{II}, \mathrm{III}, \mathrm{IV},
$$

where $T$ is the measurement time length.

Figures 5-6 (for R1 and R2, respectively) show the vertical profiles of the normalized occurrence frequency, $f_{k}$, determined in each section near the bank (axis 1) and at the channel axis (axis 3), against the relative water depth $z / h$.

Figure 5 (R1) shows that, for all the sections examined, ejection and sweep events are dominant near the bank (Figure 5a). The occurrence frequency of ejection and sweep events decreases as one moves from the free surface towards the bed. Furthermore, it can be observed in Figure 5a that near the bed - approximately at $z / h=0.2-$ 


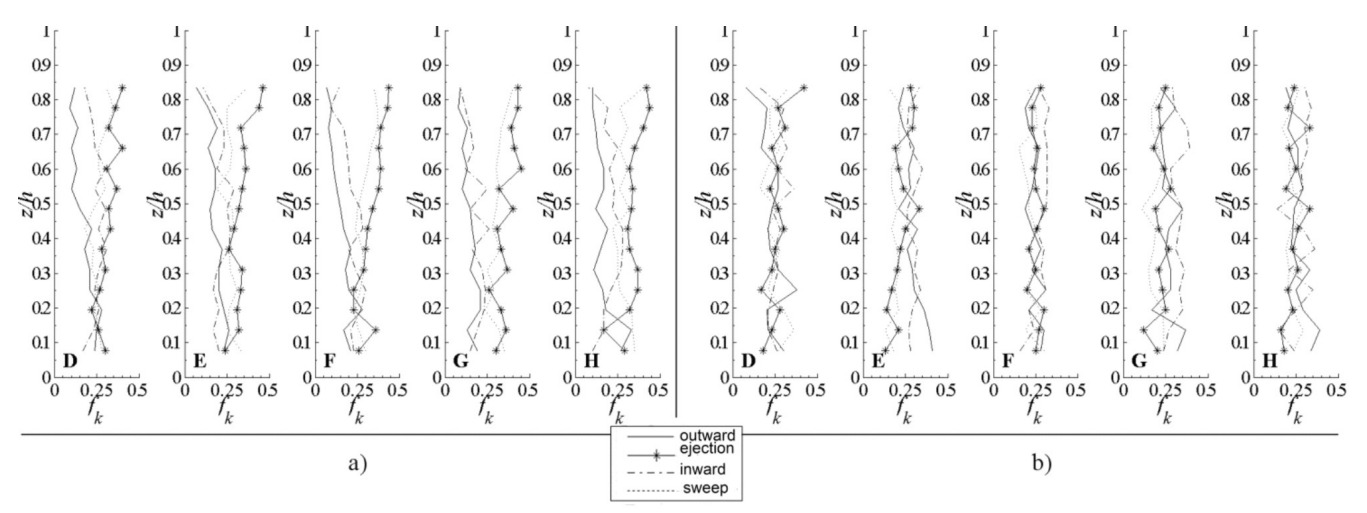

Fig. 5. Vertical profiles of the occurrence frequency of turbulent events - R1 (flat bed): a) axis 1 ; b) axis 3

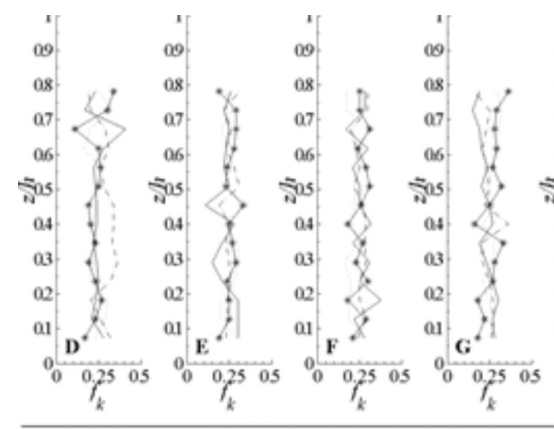

a)

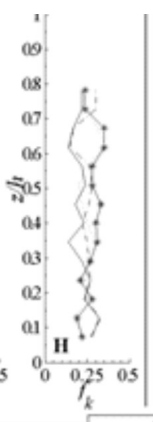

$\longrightarrow+$ enoter

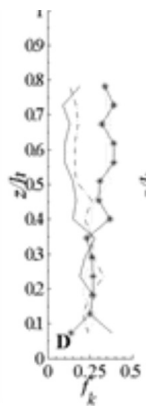

ection

mward
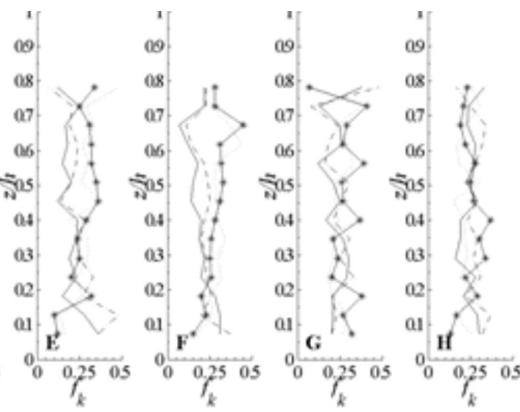

b)

Fig. 6. Vertical profiles of the occurrence frequency of turbulent events - R2 (deformed bed): a) axis 1 ; b) axis 3

the values of $f_{k}$ are higher for ejection $(k=\mathrm{II})$ and/or sweep $(k=\mathrm{IV})$ events in sections $\mathrm{E}, \mathrm{G}$ and $\mathrm{H}$, as well as for inward $(k=\mathrm{I})$ and outward $(k=\mathrm{III})$ interaction events in sections D and F. At the channel axis (Figure 5b), the occurrence frequency of each event is rather constant all along the depth. Ejection and sweep events are slightly dominant in sections $\mathrm{D}$ and $\mathrm{F}$, whereas inward $(k=\mathrm{I})$ and outward $(k=\mathrm{III})$ interaction events are prevalent in sections $\mathrm{E}$ and G. Thus, Figure 5 suggests that events falling in quadrants II and/or IV occur in sections spaced approximately $40 \mathrm{~cm}$ apart. It should also be noted that events in quadrants II and IV occur along the channel reach examined (and along the depth) as indicated by previous literature works (Yalin 1992, Kanani et al 2010).

In R2, it can be observed that (with the exception of section D) ejection and sweep events near the bank (Figure 6a) occur more frequently above $0.2 h$. Moreover, the occurrence frequency seems rather constant all along the water depth. For $z / h<0.2$, ejection and/or sweep events occur more frequently in sections $\mathrm{D}$ and $\mathrm{F}$, whereas in 
sections $\mathrm{E}, \mathrm{G}$, and $\mathrm{H}$ the values of the occurrence frequency are higher for inward and/or outward interaction events. At the channel axis (Figure 6b) ejection events are prevalent for $z / h>0.2$ (in almost all sections). Near the bed $(z / h<0.2)$, ejection events are more frequent in sections D and G, whereas in sections $\mathrm{E}, \mathrm{F}$, and $\mathrm{H}$ higher occurrence frequency values correspond to inward and/or outward interaction events. Thus, Figure 6 suggests that in R2 the events occur with the same spatial length as that observed in R1. As a result of the presence of the front of deposit, the sequence of events seems to be slightly shifted downstream.

These figures suggest that the average horizontal burst length is $\lambda_{h}=0.80 \mathrm{~m}=2 \mathrm{~B}$, which is equal to the distance $L s$ between maximum scour and the front of deposit. The mean time interval for the occurrence of consecutive ejection/sweep events at each point can be obtained as the inverse of the occurrence frequency. This implies that the mean time interval between ejection and sweep events is larger near the bed.

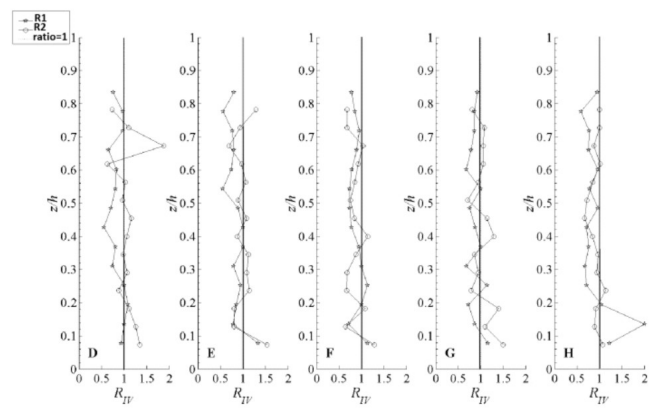

a)

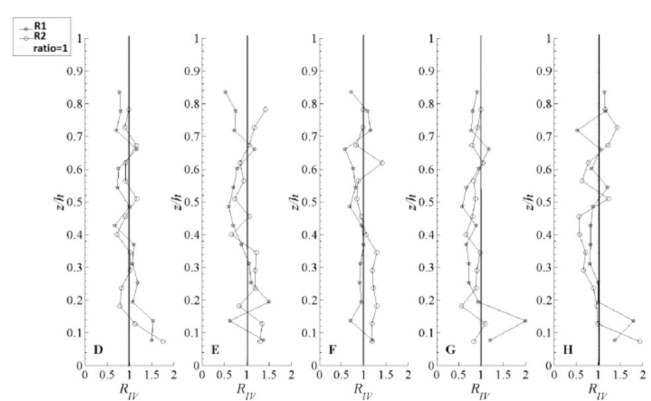

b)

Fig. 7. Vertical profiles of the ratio $R_{I V}$ : a) axis 1 ; b) axis 3

Near the free surface, especially in R1, the occurrence frequency of ejection events is greater than that of sweep events, but, as one moves towards the bed, the occurrence frequency of sweep events increases so that near the bed it is often comparable with that of ejection events. Such behaviour can be better observed in Figure 7, where the ratios between the sweep and ejection occurrence frequencies, i.e. $R_{I V}=f_{I V} / f_{I I}$, for both axes (1 and 3) are plotted against the relative water depth $z / h$. Figure 7 shows that the values of $R_{I V}$ obtained in R1 are generally lower than those obtained in R2. This suggests that the occurrence frequency of sweep events increases as the bed roughness increases. Furthermore, in $\mathrm{R} 2, R_{I V}$ is greater than 1 almost all along the depth, especially in sections $\mathrm{D}$ and $\mathrm{E}$ along axis 1 and in sections $\mathrm{D}, \mathrm{E}$, and $\mathrm{H}$ along axis 3 . 


\subsection{Joint Probability Density Distribution}

In order to distinguish between events of different magnitudes within each kind, the joint probability density function, $P_{12}$, of couples $\left[u_{1, f}^{\prime}, u_{2, f}^{\prime}\right]$, was estimated as follows (Pope 2000):

$$
P_{12}=A_{12} \cdot \exp \left[B_{12} \cdot C_{12}\right]
$$

with

$$
\begin{aligned}
& A_{12}=\left[4 \pi^{2} \cdot \overline{u_{1, f}^{\prime 2}} \cdot \overline{u_{2, f}^{\prime 2}} \cdot\left(1-\rho_{12}^{2}\right)\right]^{-0.5} ; \quad B_{12}=\frac{-0.5}{\left(1-\rho_{12}^{2}\right)} ; \\
& C_{12}=\left(\frac{u_{1, f}^{\prime 2}}{\overline{u_{1, f}^{\prime 2}}}-2 \cdot \frac{\rho_{12} \cdot u_{1, f}^{\prime} \cdot u_{2, f}^{\prime}(z, t)}{\left[\overline{\left.u_{1, f}^{\prime}\right)^{2}} \cdot \overline{u_{2, f}^{\prime 2}}\right]^{0.5}} \overline{\overline{u_{2, f}^{\prime 2}}}\right) ; \quad \rho_{12}=\frac{\overline{u_{1, f}^{\prime} \cdot u_{2, f}^{\prime}}}{\left[\overline{u_{1, f}^{\prime 2}} \cdot \overline{u_{2, f}^{\prime 2}}\right]^{0.5}},
\end{aligned}
$$

where the over-bar indicates time-averaged values.

On the plane $\left[u_{1, f}^{\prime}, u_{2, f}^{\prime}\right], P_{12}$ is represented by an ellipse with the long axis rotated according to the more frequent event. In Figures 8-9, the contour lines of $P_{12, z b}$ (at $z=$ $z_{b}$ ) estimated near the bed along axes 1 and 3 are shown for R1 and R2, respectively. In these figures, $m$ represents the angular coefficient of the long axis of the ellipse. Thus, it is possible to identify the couples of quadrants characterized by the same sign of the products $\left[u_{1, f}^{\prime} u_{2, f}^{\prime}\right]$. The peak of the distribution of $P_{12, z b}$ indicates the most probable event occurring at the corresponding measurement point. Because such a peak is not always easily distinguishable, the values of the ratio $R_{I I}=f_{I I} / f_{I V}$ (or of the ratio $R_{I I I}=f_{I I I} / f_{I}$ ) are also reported in Figures 8-9. In Figure 8 (R1) it can be seen that near the bank (axis 1) and in sections D and F the long axis of the ellipse falls in quadrants I and III $(m>0)$, and $R_{I I I}<1$. This means that events of outward interaction occur.

In sections $\mathrm{E}, \mathrm{G}$, and $\mathrm{H}$, the long axis of the ellipse is rotated so as to fall in quadrants II and IV $(m<0)$ : in sections $\mathrm{E}$ and $\mathrm{G}, R_{I I}>1$ and thus the peak of the distribution falls in quadrant II, and ejection events develop; in section $\mathrm{H}, R_{I I}<1$, so sweep events occur. At the channel axis (axis 3), it can be observed that, for each section examined, the long axis of the ellipse assumes the direction opposite to that observed near the bank: in sections D and $\mathrm{F}$ the long axis is rotated so as to fall in quadrants II and IV $(m<0)$; in sections $\mathrm{E}, \mathrm{G}$, and $\mathrm{H}$ the long axis falls in quadrants I and III $(m>0)$. In section $\mathrm{D}$, the peak of the distribution is not clearly distinguishable, but $R_{I I}>1$ and ejection events occur; in section F, $R_{I I}<1$ and sweep events occur. Events of outward interaction develop in sections $\mathrm{E}$ and $\mathrm{H}\left(R_{I I I}<1\right)$ and events of inward interaction occur in section $\mathrm{G}\left(R_{I I I}>1\right)$.

The contour lines of $P_{12, z b}$ reported in Figure 9 (R2 run) show that, near the bank (axis 1), the angular coefficient of the long axis of the ellipse, $m$, is negative in sections $\mathrm{D}$ and $\mathrm{F}$, and positive in sections $\mathrm{E}, \mathrm{G}$, and $\mathrm{H}$. In almost all sections, the peak of the 

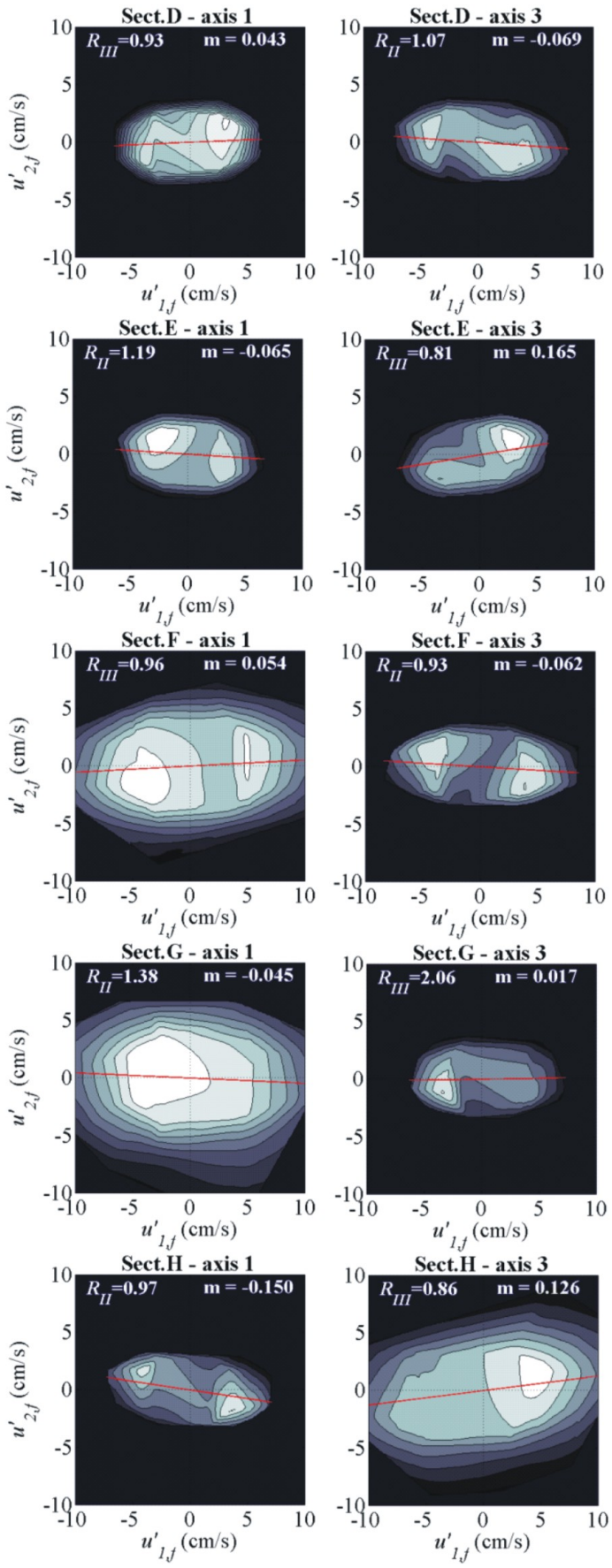

$$
P_{12}\left(z_{b}\right)
$$

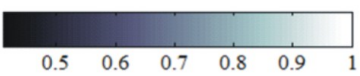

Fig. 8. Contour lines of $P_{12, z b}-$ flat bed 

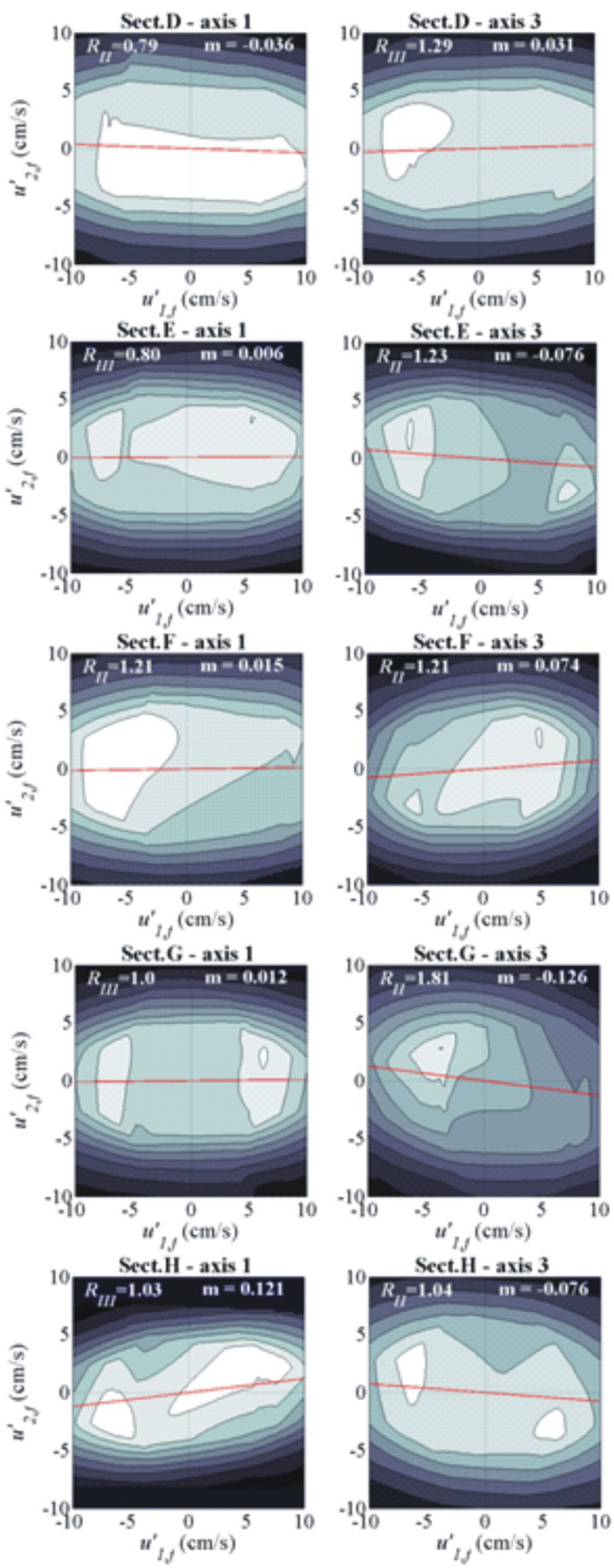

$$
P_{l 2}\left(z_{b}\right)
$$$$
\begin{array}{llllll}
0.5 & 0.6 & 0.7 & 0.8 & 0.9 & 1
\end{array}
$$

Fig. 9. Contour lines of $P_{12, z b}-$ deformed bed 
distribution of $P_{12, z b}$ is not clearly distinguishable, but $R_{I I}<1$ in section D and $R_{I I}>1$ in section F, so sweep events occur in section $\mathrm{D}$, and ejection events occur in section F. In sections $\mathrm{G}$ and $\mathrm{H}$, events of inward interaction develop $\left(R_{I I I}>1\right)$. Events of outward interaction can be observed in section $\mathrm{E}\left(R_{I I I}<1\right)$.

Thus, Figures 8-9 confirm that, under the (initial) flat-bed conditions (R1), events in quadrants II and/or IV occur with a spatial length of $40 \mathrm{~cm}$, and the entire horizontal burst cycle has a length of about $80 \mathrm{~cm}(\approx 2 \mathrm{~B})$. The entire burst cycle develops alternatively near the bank (axis 1) and at the channel axis (axis 3). Under deformed-bed conditions (R2), the spatial length of the entire burst cycle is the same as that in R1 (i.e. the same as the "initial bursting spatial length"). However, the burst cycle is slightly shifted in the streamwise direction, downstream of the front of deposit.

\subsection{Kinetic Energy of the Mean Flow and Turbulent Kinetic Energy}

A further important element in the analysis of the evolution of bursting events is the distribution of the turbulent energy budget.

As it should be clear from the Introduction, the bursting motions associated with events of quadrants II and IV (i.e. ejections and sweeps) are closely connected to turbulent kinetic energy production (Lu and Willmarth 1973, Pope 2000). Thus, for each run, the horizontal kinetic energy of the mean flow, $K$, and turbulent kinetic energy, $K^{\prime}$, were estimated as:

$$
K=\frac{1}{2} \sum_{i=1}^{2} U_{i, f}^{2}, \quad K^{\prime}=\frac{1}{2} \sum_{i=1}^{2}\left[\overline{u_{i, f}^{\prime 2}}\right],
$$

where $U_{i, f}$ is the time-averaged velocity component of the filtered time series.

Figures 10-11 show the contour lines of $K$ and $K^{\prime}$ estimated in each section for $\mathrm{R} 1$ and R2, respectively. These figures show the classical distributions of $K$ and $K^{\prime}$ : the maximum of $K$ nearly coincides with the minimum of $K^{\prime}$, and positive/negative gradients of $K$ correspond to negative/positive gradients of $K^{\prime}$. In R1 (Figure 10), $K$ (Figure 10a) assumes high values near the free surface between axes 2 and 3 in sections $\mathrm{D}$ and $\mathrm{F}$, as well as between axes 2 and 4 in sections $\mathrm{E}$ and $\mathrm{H}$. Thus, higher values of $K$ occur in sections spaced $40 \mathrm{~cm}$ apart. The turbulent kinetic energy, $K^{\prime}$, (Figure $10 \mathrm{~b}$ ) assumes low values near the free surface and increases in value as one progresses towards the bed. Higher values of $K^{\prime}$ are found especially in the central area of sections $\mathrm{E}, \mathrm{G}$, and $\mathrm{H}$, as well as near the banks in sections D and F. Thus, the behaviour of the turbulent kinetic energy is symmetrical with respect to the channel axis. The pattern observed suggests that two eddies form near the banks and near section D. They grow moving downstream and towards the bed, and a new eddy forms at the channel axis (between sections $\mathrm{F}$ and $\mathrm{H}$ ) when they reach their maximum dimension. When the eddy explodes, it releases its own energy to particles placed over the bed. This further supports the theory (Yalin 1992 - see also Kanami et al 2010) that the perpetual action of the aforementioned turbulence sequence enhances the entrainment and movement 

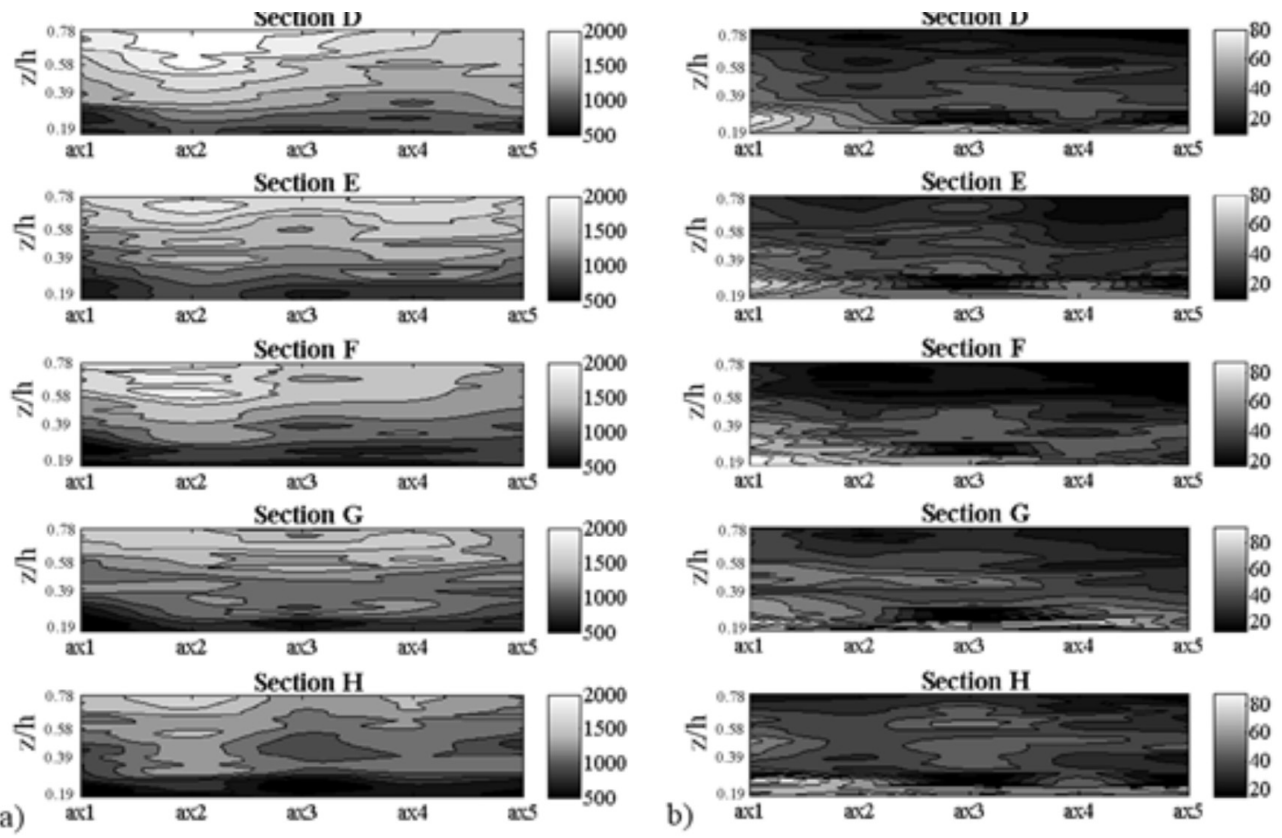

Fig. 10. Contour maps - R1 (flat bed): a) kinetic energy of the mean flow, $\left.K\left(\mathrm{~cm}^{2} / \mathrm{s}^{2}\right) ; \mathrm{b}\right)$ turbulent kinetic energy, $K^{\prime}\left(\mathrm{cm}^{2} / \mathrm{s}^{2}\right)$
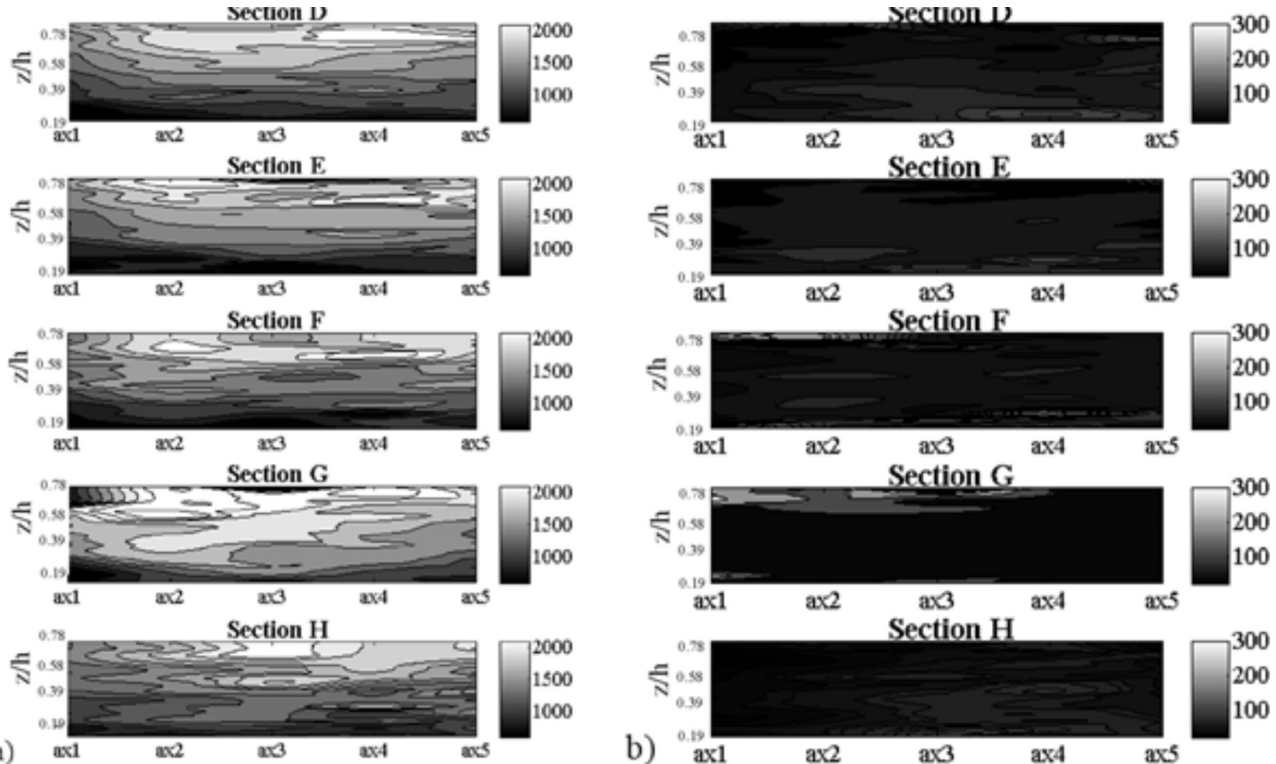

Fig. 11. Contour maps - R2 (deformed bed): a) kinetic energy of the mean flow, $K\left(\mathrm{~cm}^{2} / \mathrm{s}^{2}\right)$;

b) turbulent kinetic energy, $K^{\prime}\left(\mathrm{cm}^{2} / \mathrm{s}^{2}\right)$ 
of sediment so that the bed tends to sustain a corresponding "periodic" deformation. In R2 (Figure 11), both $K$ and $K^{\prime}$ show a trend similar to that observed in R1, but slightly shifted in the streamwise direction. In particular, higher values of $K$ (Figure 11a) are found at the free surface, near the banks in sections E, F, and G, whereas in sections $\mathrm{D}$ and $\mathrm{H}$ they are found near the channel axis.

Figure $11 \mathrm{~b}$ shows that high values of the turbulent kinetic energy, $K^{\prime}$, are found not only near the bed, as well as in R1 but also near the free surface and near the banks in sections F and G. This could be due to the influence of the front of deposit to the eddy growing. Furthermore, it would suggest that an eddy forms downstream of the front of deposit.

\subsection{Reynolds Shear Stress}

Figure 12 (a-b) reports, for both runs, the plane distribution of the horizontal Reynolds shear stress, $\tau_{12, z_{b}}$, determined near the bed (at $z=z_{b}$ ) as follows:

$$
\tau_{12, z_{b}}=-\rho \cdot\left[\overline{u_{1, f}^{\prime} \cdot u_{2, f}^{\prime}}\right]_{z=z_{b}},
$$

where $\rho$ is the fluid density.
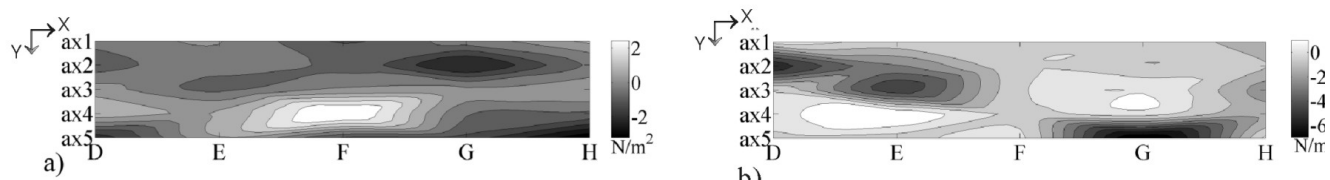

b)

Fig. 12. Distribution of the Reynolds stress $\tau_{12, z_{b}}$ : a) flat bed; b) deformed bed

It can be observed that the sign of the Reynolds stress changes along the channel reach. In particular, in R1 (Figure 12a) high positive values of $\tau_{12, z_{b}}$ are found in sections D and F near the right bank, whereas high negative values of $\tau_{12, z_{b}}$ are found in section $\mathrm{G}$ near the left bank. In R2 (Figure 12b), two negative peak values of $\tau_{12, z_{b}}$ are found near the banks between sections $\mathrm{D}$ and $\mathrm{E}$, as well as between sections $\mathrm{G}$ and $\mathrm{H}$ (i.e. negative values of $\tau_{12, z_{b}}$ are found in correspondence of the pools).

The pattern observed suggests that the Reynolds shear stress deviates from its standard linear distribution because of flow acceleration.

High positive values of $\tau_{12, z_{b}}$ are observed near the right bank in section $\mathrm{E}$ and near the channel axis in section G. In particular, along the channel axis, as one passes from section $\mathrm{D}$ to section $\mathrm{H}, \tau_{12, z_{b}}$ assumes a negative peak value in section $\mathrm{E}$; then, it decreases in value and changes the sign approximately in section $\mathrm{F}$ (a positive peak value is found in section $\mathrm{G}$ ); and in section $\mathrm{H}, \tau_{12, z_{b}}$ is again negative. This behavior suggests that high values of the Reynolds shear stress are found downstream of the front of deposit where the burst cycle initiation is enhanced. 


\section{Conclusions}

In this study the occurrence of horizontal turbulent events was experimentally explored over flat (initial or pre-deformed) and deformed beds.

The turbulent events were qualitatively described by the conditioned quadrant analysis. The principal conclusions arising from the analysis are the following:

- In R1 (pre-deformed-bed conditions), ejection events are more frequent than sweep events near the free surface. As one progresses towards the bed, the occurrence frequency of sweep events increases so that near the bed the occurrence frequency of both types of events is comparable. In R2 (deformed-bed conditions), sweep events are more frequent than ejection events almost all along the depth.

- In R1, ejection and/or sweep events occur with a spatial length of $40 \mathrm{~cm}$, and the spatial length of an entire horizontal burst cycle scales with the channel width $\left(\lambda_{h}=80 \mathrm{~cm} \approx 2 \mathrm{~B}\right)$. Furthermore, the burst cycle develops alternatively near the bank and at the channel axis. Thus, the spatial length obtained in R1 could be assumed as the "initial bursting spatial length." This spatial length of the burst cycle compares well with the length $(L s)$ of the sequence of scour holes/deposit fronts found on the bed in R2 (deformed-bed conditions). As a result of the presence of the deposit front, the burst cycle seems to shift slightly in the streamwise direction, downstream of the front of deposit.

- The patterns of the mean flow kinetic energy $(K)$ and turbulent kinetic energy $\left(K^{\prime}\right)$ suggest that in R1 (pre-deformed-bed conditions), $K$ assumes high values near the free surface in sections spaced $40 \mathrm{~cm}$ apart. The turbulent kinetic energy, $K^{\prime}$, assumes low values near the free surface, but increases as one progresses towards the bed. Thus, the conversion of kinetic energy into turbulent kinetic energy occurs as one approaches the bed, where the turbulent energy assumes higher values. In R2 (deformed-bed conditions), both $K$ and $K^{\prime}$ show a trend similar to that in R1, but slightly shifted downstream. The patterns of $K$ and $K^{\prime}$ suggest that, in $\mathrm{R} 2$, an eddy forms downstream of the front of deposit.

The aforementioned behavior is also confirmed by the distribution of the horizontal Reynolds shear stress. High values of the Reynolds shear stress are found downstream of the front of deposit.

In summary, the experimental results presented here show that, under deformed-bed conditions, the length of the burst cycle is the same as that observed under pre-deformed bed condition ("initial bursting spatial length"). However, as a result of bed deformation, the burst cycle is slightly shifted in the streamwise direction. Furthermore, the analysis demonstrates that, under deformed-bed conditions, the front of deposit becomes the "location of preference" for low-frequency high-spectrum motions. This behavior supports Yalin's (1992) claim that bed forms lead to the "regularization" of horizontal turbulence and the presence of their "holes" enhances the roll-up of horizontal vortices above them. 
Thus, the present results confirm that bed deformation could be a kind of imprinting of the aforementioned complicated flow turbulent pattern. This is consistent with Yalin's (1992) findings.

It should be noted that the results obtained are restricted to the experimental conditions examined. Further analyses have to be conducted for different hydraulic conditions, and thus for different $B / h$ and $h / k_{s}$ ratios, to investigate different aspects of horizontal bursts and their morphological consequences.

\section{Acknowledgements}

Financial support from FFR2013 is gratefully acknowledged. The author would also like to express her thanks to V. Sammartano for his help in conducting the experiments and data elaboration.

\section{References}

Adrian R. J., Marusic I. (2012) Coherent structures in flow over hydraulic engineering surfaces, J. Hydr. Res., 50 (5), 451-464.

Albayrak I. (2008) An experimental study of coherent structures, secondary currents and surface boils and their interrelation in open-channel flow, Ph.D. Thesis, $\tilde{\mathrm{A}} \%$ ocole Polytechnique FÃddÃ drale de Lausanne, no. 4112: 281 doi: 10. 5075/epflthesis-4112.

ASCE Task Committee on Flow and Sediment Transport over Dunes (2002) Flow and Transport over Dunes, J. Hydr. Div, 92 (HY3), 51-64.

Balakumar B. J., Adrian R. J. (2007) Large-and very-large-scale motions in channel and boundary-layer flows, Philos. Trans. R- Soc. Lond. A, 365, 665-681.

Bennet S. J., Best J. L. (1995) Mean flow and turbulence structure over fixed, two-dimensional dunes: Implication for transport and dune stability, Sedimentology, 42, 491-513.

Bennet S. J., Bridge J. S., Best J. L. (1997) Fluid and sediment dynamics of upper stage plane beds,. J. Geoph. Res., 103 (C1), 1239-1274.

Cantwell B. J. (1981) Organized Motion in Turbulent Flow, Ann. Review Fluid Mechanics, 13, 457-515.

Carollo G., Ferro V., Termini D. (2005) Analyzing turbulence in gravel bed channels, J. Hydr. Eng., 131 (12), 1050-1061.

Cellino M., Lemmin U. (2004) Influence of coherent flow structures on the dynamics of suspended sediment transport in open-channel flow, J. Hydr. Eng., 130 (11), 1077-1088.

Cellino M., Graf W. H. (1999) Sediment-laden flow in open-channels under noncapacity and capacity conditions, J. Hydr. Eng., 125 (3), 455-462.

Colombini M., Seminara G., Tubino M. (1987), Finite-amplitude alternate bars, J. Fluid Mechanics, 181, 213-232.

Da Silva A. M. F. (2006) On why and how river meander, J. Hydr. Res., 44 (5), 579-590.

Garcìa M. H., Nino Y., Lopez F. (1996) Laboratory observations of particle entrainment into suspension by turbulent bursting, in coherent flow structures in open channels, edited by P. J. Ashworth, S. J. Bennett, J. L. Best and S. J. McLelland, Wiley, Chichester, chap. 3, 63-68.

Grass A. J. (1971) Structural Features of Turbulent Flow Over Smooth and Rough Boundaries, J. Fluid Mechanics, 50 (2), 233-255.

Holmes R. R., Garcìa M. (2008) Flow over bedforms in a large sand-bed river: A Field investigation, $J$. Hydr. Res., 46 (3), 322-333. 
Hosoda T., Sakurai T., Muramoto Y. (1999) 3-D computation of unsteady flows in compound open channels with horizontal vortices and secondary currents, J. Hydroscience and Hydraulic Engineering JSCE, 17 (2), 87-96.

Kanani A., Ahmari H., Ferreira da Silva A. M. (2010) Investigation of horizontal coherent structures in a shallow open-channel flow using velocity signal decomposition, Riverflow 2010-, Germany, 1059-1066.

Lewalle J., Delville J., Bonnet J. P. (2000) Decomposition of mixing layer turbulence into coherent structures and background fluctuations, Flow, Turbulence and Combustion, 64, 301-328.

Lu S. S., Willmarth W. W. (1973) Measurements of the Reynolds stress in a turbulent layer, J. Fluid Mechanics, 60 (3), 481-511.

Lyn D. A. (1993) Turbulence measurements in open-channel Flows over artificial bed forms, J. Hydr. Res., 119 (3), 306-326.

Mazumder B. S., Palm D. K., Ghoshal K., Ojha S. (2009) Turbulence statistics of flow over isolated scalene and isosceles, J. Hydr. Res., 47 (5), 626-637.

Nadaoka K., Yagi H. (1998) Shallow-water turbulence modeling and horizontal large eddy computation of river flow, J. Hydr. Eng. ASCE, 124 (5), 493-500.

Nakagawa H., Nezu I. (1981) Structure of space-time correlations of bursting phenomena in an open-channel flow, J. Fluid Mechanics, 104, 1-43.

Nelson J. M., Shreve R. L., Mclean S., Drake T. G. (1995) Role of near-bed turbulence structure in bed load transport and bed form mechanics, Water Res. Res., 31 (8), 2071-2086.

Nezu I., Nakagawa H. (1993) Turbulence on open channel flows, A. A. Balkema Publishers, Rotterdam, the Netherlands.

Nezu I., Nakayama T. (1997) Space-time correlation structures of horizontal coherent vortices in compound open-channel flows by using particle-tracking velocimetry, J. Hydr. Res., 35 (2), 191-208.

Nezu I., Onitsuka K., Iketani K. (1999) Coherent horizontal vortices in unsteady depth-varying open-channel flows. Hydraulic Modeling (ed. Singh et al), Water Res. Pub. Colorado, 17-32.

Nezu I., Onitsuka K. (2002) Turbulent structures in partly vegetated open-channel flows with LDA and PIV measurements, J. Hydr. Res., 39 (6), 629-642.

Nezu I., Rodi W. (1986) Open-channel flow measurements with a laser Doppler anemometer, J. Hydr. Eng., 123 (5), 335-355.

Nezu I., Sanjou M., Goto K. (2003) Coherent horizontal vortices in unsteady depth-varying compound open-channel flows, XXX IAHR Congress, Vol. 1, Thessaloniki, 57-64.

Nikora V. I., Goring G. (1999) On the relationship between Kolmogorov's and generalized structure functions in the inertial subrange of developed turbulence, J. Phys. Math. Gen., 32, 4963-4969.

Nikora V. I., Smart G. M. (1997) Turbulence characteristics of New-Zealand gravel-bed rivers, J. Hydr. Eng., 120 (8), 764-773.

Pope S. B. (2000) Turbulent flows, Cambridge University Press.

Robinson S. K. (1991) Coherent motions in the turbulent layer, Ann. Review Fluid Mechanics, 23, 601-639.

Rodríguez J. F., Garcìa M. H. (2008) Laboratory measurements of 3-D flow patterns and turbulence in straight open channel with rough bed, J. Hydr. Res., 46 (4), 454-465.

Sanjou M., Nezu I. (2009) Turbulence structure and coherent motion in meandering compound open-channel flows, J. Hydr. Res., 47 (5), 598-610.

Shvidchenko A. B., Pender G. (2001). Macroturbulent structure of open-channel flow over gravel beds, Water Res. Res., 37 (3), 709-719.

Steffler P., Rajaratnam N., Peterson A. W. (1985) LDA measurements in open channel, J. Hydr. Eng., 111 (1), 119-130. 
Sukhodolov A. N., Nikora V., Katolokiv V. M. (2011) Flow dynamics in alluvial channels: the legacy of Kirill V. Grishanin, J. Hydr. Res., 49 (3), 285-292.

Tamai A., Asaeda T., Ikeda H. (1986) Study on generation of periodical large surface eddies in a composite channel flow, Water Res. Res., 22 (7), 1129-1138.

Termini D. (2005) Experimental investigation on the horizontal turbulence and the bed deformation: preliminary results, Proceedings of International Symposium on Stochastic Hydraulics, IAHR Congress, 23-24 May, Nijmegen - The Netherlands.

Termini D., Lo Re C. (2006) Analysis of the relation between the flow "horizontal" turbulence and the bed deformation, Proceedings of International Symposium on Sediment Dynamics and the Hydromorphology of Fluvial Systems, Dundee (Scotland) 3-7 July, 73-79.

Termini D., Sammartano V. (2007) Analysis of the role of turbulent structure in bed-forms formation in a rectilinear flume, 32nd Congress of IAHR, "Harmonizing the Demands of Art and Nature in Hydraulics”, Venice, Italy, 1-6 July 2007.

Termini D., Sammartano V. (2008) Experimental analysis of relation between coherent turbulent structures and bed-forms formation, Archives of Hydro-Engineering and Environmental Mechanics, 55 (3-4), 125-143.

Termini D., Sammartano V. (2009) Experimental observation of horizontal coherent turbulent structures in a straight flume, Proceedings of River, Coastal and Estuarine Morphodynamics - RCEM 2009, 21-29 September, Santa Fe City, Argentina.

Utami T., Ueno T. (1991) Experimental Study on the Compound Meandering Channel Flow Using Flow Visualization and Picture Processing, J. Hydroscience and Hydr. Eng., 9 1, pages?.

White B. L., Nepf H. M. (2007) Shear instability and coherent structures in shallow flow adjacent to a porous layer, J. Fluid Mechanics, 593, 1-32.

Yalin M. S. (1992) River Mechanics, Pergamon Press, London.

Yalin M. S., Da Silva A. M. F. (2001) Fluvial Processes, IAHR Monograph, IAHR, Delft, The Netherlands.

Yokosi S. (1967) The structure of river turbulence, Bull. Disaster Prevention Res. Inst., Kyoto Univ., 17 (2), No. 121, October. 